\title{
Out of the Box: Needs-Driven Passion Meets Population Health
}

An editorial in a recent double issue of Seminars in Oncology dedicated to Cuba commented that, in contrast to most current therapeutic research that provides relatively little new information, Cuban research represents " . . . truly out of the box thinking, crafted in a country where resource limitations have clearly incentivized novel approaches." Indeed, this is a hallmark of Cuba's scientific sector, forging ahead in a developing island nation under six decades of US embargo and battered by the vicissitudes of global, regional and national economic fluctuations.

But "out of the box" may only be the entry point into a broader conceptualization that calls upon science to generate discoveries not for its sake alone, but in response to the critical needs of population and planetary health and wellbeing. Today, in addition to medicine and vaccine development and production, priorities for Cuban science include food security, sustainable energy, climate adaptation and society-wide incorporation of information technologies. Several of these notions are in fact incorporated into draft constitutional reforms approved by parliament this month and now subject to a national referendum.

\section{What place, in scholarship for passion? Is it truly 'neutral' to remain dispassionate before unnecessary suffering? Or is such studied neutrality really a concession to the inevitability of inequalities of outcome? \\ -Paul Farmer, Infections and Inequalities: The Modern Plagues}

In other words, this approach argues that science, although evidence-based, is not neutral. New knowledge, excellence in research and improved outcomes result from scientists' expertise, environment and persistence....but also from the passion derived from how they view their role in society. And passion for equitable growth and sustainable development put science squarely at the center of any fight for social justice. In one way or another, all the articles selected for Editors' Choice in this issue, as well as several others, touch upon this theme.

This July, our journal inaugurates a new series profiling outstanding women in Cuban health, science and technology. Cuba's scientific sector today employs more than 86,000 people, more than half of whom are women. Their contribution to scientific and social development over time has been extraordinary, as we have come to observe. One outstanding example is pictured on our cover: Dr Laura Martínez de Carvajal (1869-1941), Cuba's first woman doctor. The eldest daughter of a wealthy Spanish family, she defied the social conventions of the day regarding women's roles and entered the University of Havana at age 14 . She graduated medicine at 19 , on July 5,1889 , going on to also become Cuba's first woman ophthalmologist. Today, the original photo of this pioneering woman hangs in the halls of the Cuban Academy of Sciences. To contextualize this MEDICC Review series, our first interview (and an Editors' Choice) is with sociologist Marta Núñez, who shares insightful reflections on the history and current status of women in Cuba in every aspect of life.

Two other Editors' Choice articles highlight research in Cuba's burgeoning biotech sector, which has already made important contributions to population health at home and abroad. Cuban research institutions employ a "closed-loop" approach, identifying important problems, developing and testing new products to address them, and manufacturing such products in sufficient quantity, not only to cover domestic needs, but for export (completing the sustainability loop). In his article, Camacho-Rodríguez describes the likely mechanisms through which Cuba's Heberprot-P prevents amputations due to diabetic foot ulcers. Now eligible for clinical trials in the USA, Heberprot-P has been shown effective in healing such ulcers, reducing morbidity, disability and deaths among the increasingly numerous diabetic population. And one of Cuba's most eminent immunologists, Ochoa-Azze, presents an assessment of the field effectiveness of a Cuban vaccine against meningitis serogroups $B$ and C. VA-MENGOC-BC, was developed by Cuba's Finlay Vaccine Institute in the 1980s in response to a nationwide epidemic of meningitis $B$, particularly affecting youngsters. The vaccine became the world's first effective vaccine against this particular serogroup, and its use in Cuba and abroad is documented and analyzed here.

A fourth Editors' Choice, by Wright, explores researchers' perceptions of obstacles to studying chronic kidney disease of nontraditional origins (CKDnt). Readers may remember the 2014 MEDICC Review special issue on this new form of nephropathy that has ravaged poor agricultural communities in Central America and elsewhere. Prior to that, we published the first major epidemiological study of the problem in El Salvador, an article which El Salvador's then Minister of Health, Dr María Isabel Rodríguez, presented as evidence to the UN High-level Meeting on Non-Communicable Diseases (NCD), successfully arguing that CKDnt should be included in WHO's strategy for reducing the burden of NCDs worldwide, enunciated in the 2011 Political Declaration on the Prevention and Control of NCDs.

The Viewpoint by Mas, a reprint from the Cuban magazine $\mathrm{Mu}$ jeres, deserves special attention: Since 1989, World Population Day (WPD) has been celebrated on July 11 to raise public and political awareness of urgent population issues. Appropriately, the WPD 2018 theme is Family Planning is a Human Right, and Más's Viewpoint addresses these issues (particularly informed decisionmaking) in Cuba, inspired by a workshop held by Cuba's Center for Demographic Studies.

Finally, we at MEDICC Review are devastated by the death of $\mathrm{Dr}$ José Baudilio Jardines Méndez, eminent public health physician, medical educator and codeveloper of Cuba's Virtual Public Health Campus (an indispensable tool for online learning in public health). He was Cuba's Vice Minister of Health at a time when few believed US-Cuba cooperation was possible, and was a prime mover in the creation of our publisher, Medical Education Cooperation with Cuba (MEDICC). We have lost a great humanitarian, colleague and friend. -1 -

\section{The Editors}

PS Access online articles on the brand new MEDICC Review website, premiering with this issue at www.mediccreview.org Your opinions welcome on our new look. 